\title{
PROTEIN PHOSPHORYLATION DURING AFTERDISCHARGE IN PEPTIDERGIC NEURONS OF APLYSIA ${ }^{1}$
}

\author{
K. R. JENNINGS, L. K. KACZMAREK, ${ }^{2}$ R. M. HEWICK, ${ }^{3}$ W. J. DREYER, AND F. STRUMWASSER ${ }^{4}$ \\ Division of Biology, California Institute of Technology, Pasadena, California 91125
}

Received June 10, 1981; Revised September 16, 1981; Accepted October 9, 1981

\begin{abstract}
The bag cells (BC) of Aplysia are a group of peptidergic neurons that respond to brief electrical stimulation by producing a prolonged afterdischarge of synchronous action potentials. We have demonstrated previously that the cyclic nucleotide, cyclic $3^{\prime}: 5^{\prime}$-adenosine monophosphate (cyclic AMP), plays a role in the genesis of the bag cell afterdischarge and that the microinjection of the catalytic subunit of cyclic AMP-dependent protein kinase increases the excitability of bag cell neurons in culture.

In this paper, we present evidence that the phosphorylation state of at least two proteins (proteins BC-1 and BC-2) are enhanced after the onset of afterdischarge. One of these proteins, BC-2 (approximately 21,000 daltons), undergoes cyclic AMP-stimulated phosphorylation in cell-free extracts in vitro and is the major substrate in bag cell tissues for exogenous cyclic AMP-dependent protein kinase catalytic subunit. This protein undergoes a substantial change in phosphorylation at 20 min into the afterdischarge using both bag cells prelabeled with $\mathrm{Na}_{2} \mathrm{H}^{32} \mathrm{PO}_{4}$ and a "back phosphorylation" (postlabeling) procedure. No change could, however, be detected early (2 min) in the afterdischarge with either technique for this protein. We have determined that BC-2 phosphoprotein is apparently specific to bag cell tissue and is not the precursor to the bag cell neurosecretory peptide previously described. We also have determined the amino acid composition and present a partial sequence of the $\mathrm{NH}_{2}$ terminus obtained from $100 \mathrm{pmol}$ of protein eluted from a sodium dodecyl sulfate-polyacrylamide gel band.

Using the method of prelabeling phosphoproteins in bag cells with $\mathrm{Na}_{2} \mathrm{H}^{32} \mathrm{PO}_{4}$, we observed an $82 \%$ increase in phosphorylation of a 33,000-dalton protein (BC-1) at $2 \mathrm{~min}$ and a $69 \%$ increase at 20 min into the afterdischarge. In vitro labeling with $\left[\gamma^{32} \mathrm{P}\right] \mathrm{ATP}$ (adenosine triphosphate) demonstrated that this protein undergoes cyclic AMP-dependent phosphorylation and that its phosphorylation also was enhanced markedly by exogenous cyclic AMP-dependent protein kinase. BC1 does not appear to be a phosphoprotein unique to bag cells and, from Coomassie blue staining, is a minor component in this tissue.

We have described two proteins in bag cell tissues whose phosphorylation state is altered by both cyclic AMP with in vitro labeling and by afterdischarge in the intact bag cell cluster. A change in the phosphorylation state of these proteins may be related to the electrical events of afterdischarge or to its biochemical sequelae.
\end{abstract}

Many neuronal and neuroendocrine cells undergo excitability changes that are thought to involve cyclic nucleotides or calcium ions. In eucaryotic cells, the only known means by which cyclic nucleotides act is by stimulating the activity of endogenous protein kinase en-

\footnotetext{
'We would like to thank Dr. M. Hunkapiller for performing the electroelution of the $\mathrm{BC}-2$ protein from the polyacrylamide gel. We would also like to thank Dr. M. Kennedy and Dr. A. Chiu for their comments on an earlier version of the manuscript. The research reported in this paper was supported by National Institutes of Health Grants NS 13896 and 15183 to F. S. K. R. J. is a Gordon Ross Medical Foundation Fellow.
}

zymes which leads to the phosphorylation of specific protein substrates. Changes in the state of protein phosphorylation have been hypothesized to be responsible for altering the ionic conductances and, hence, the state of excitability of individual nerve cells (Greengard, 1978).

It has been shown previously that the cyclic nucleotide,

\footnotetext{
${ }^{2}$ Present address: Department of Pharmacology, Yale University School of Medicine, New Haven, CT 06510.

${ }^{3}$ Present address: The Genetics Institute, 225 Longwood Avenue, Boston, MA 02115.

${ }^{4}$ To whom correspondence should be addressed.
} 
cyclic AMP, is involved in the excitation of the peptidergic bag cell neurons of Aplysia (Kaczmarek et al., 1978). The bag cells comprise two symmetrical clusters of neurons at the base of each pleurovisceral connective nerve. They are anatomically distinct from the remainder of the abdominal ganglion and their processes extend rostrally for about $1 \mathrm{~cm}$ anteriorly into the pleurovisceral connective nerve. Following brief electrical stimulation of this nerve, the bag cells are triggered into a long lasting ( $\sim 30-\mathrm{min}$ ) afterdischarge that is synchronous in all of the cells of a cluster (Kupfermann and Kandel, 1970). This afterdischarge is associated with a $200 \%$ increase in cyclic AMP levels within the cluster, can be initiated by cyclic AMP analogs in the absence of nerve stimulation, and is prolonged by phosphodiesterase inhibitors (Kaczmarek et al., 1978). We also have shown that isolated bag cells in cell culture respond to microinjection of cyclic AMP analogs or the catalytic subunit of the cyclic AMPdependent protein kinase with enhanced calcium action potentials and that this change is associated with an increase in input resistance (Kaczmarek et al., 1980; Kaczmarek and Strumwasser, 1980).

Recently, alterations in protein phosphorylation correlated with long term potentiation of electrically evoked activity in the hippocampal slice (Browning et al., 1979) as well as with serotonin application to the isolated facial motor nucleus (Dolphin and Greengard, 1981) have been described in mammals.

Although protein phosphorylation has been examined in whole abdominal ganglia from Aplysia by previous workers (Levitan and Barondes, 1974), a characterization of all of the major substrate phosphoproteins of protein kinase within a homogeneous population of cells, such as the clusters of bag cell neurons, has not been carried out previously. We have, therefore, investigated the substrates of protein phosphorylation in the neuroendocrine bag cells of Aplysia californica.

We present evidence that there exists endogenous cyclic AMP-dependent protein kinase in a crude membrane fraction prepared from bag cell tissues. The protein kinase catalytic subunit from bovine heart, previously demonstrated by intracellular injection to enhance calcium action potentials in cultured bag cell neurons (Kaczmarek et al., 1980), is shown to phosphorylate the same protein substrates that are phosphorylated by the endogenous kinase.

We find that the major substrate of protein phosphorylation in bag cell (BC) tissue is an apparently bag cellspecific, membrane-associated, phosphoprotein with a molecular weight of approximately 21,000 . This protein (BC-2) undergoes a major change in phosphorylation state during afterdischarge and therefore may be involved in either the changes in excitability that occur during afterdischarge or in some other aspect of neurosecretion or cellular metabolism.

In addition, another protein, $\mathrm{BC}-1$ (33,000 daltons), in bag cells prelabeled with ${ }^{32} \mathrm{P}$ as sodium orthophosphate for 22 to $24 \mathrm{hr}$ undergoes an early increase in phosphorylation with afterdischarge.

\section{Materials and Methods}

Protein kinase catalytic subunit phosphorylation studies. For the measurement of substrates for catalytic subunit in bag cell homogenates, bag cell organs (intact bag cell clusters and surrounding connective tissue) were dissected away from the remainder of the abdominal ganglion and the pleuroabdominal connective nerves. Clusters were homogenized in $50 \mathrm{~mm}$ sodium acetate buffer ( $\mathrm{pH} 6.5$ ) containing $10 \mathrm{~mm}$ magnesium chloride, 1 $\mathrm{mm}$ zinc acetate, and $1 \mathrm{~mm}$ theophylline on ice. Zinc was included to inhibit endogenous phosphatase activity (Weller, 1979). The reaction was initiated within 1 to 2 min of homogenization by adding $50 \mu \mathrm{l}$ of homogenate to plastic tubes containing $20 \mu \mathrm{l}$ of $70 \mu \mathrm{M}\left[\gamma^{-32} \mathrm{P}\right] \mathrm{ATP}$ (25 $\mathrm{Ci} / \mathrm{mM}, \mathrm{ICN}$ ) and 25 units of catalytic subunit of protein kinase (Sigma) at $24^{\circ} \mathrm{C}$. Controls contained an equivalent volume of buffer replacing protein kinase. After $1 \mathrm{~min}$, the reaction was terminated by the addition of $75 \mu \mathrm{l}$ of a solution containing $10 \%$ glycerol, $2 \%$ sodium dodecyl sulfate (SDS), $5 \% \beta$-mercaptoethanol, and $0.001 \%$ bromphenol blue followed by heating at $90^{\circ} \mathrm{C}$ for $15 \mathrm{~min}$.

Gel electrophoresis. The solubilized proteins were separated on $10-\mathrm{cm}$-long SDS-polyacrylamide $(10 \%)$ slab gels using Tris/glycine buffer as described by Rudolph and Kreuger (1979). Electrophoresis was carried out at $100 \mathrm{~V}$ (constant voltage) for 4 to $5 \mathrm{hr}$. Molecular weight standards (lysozyme, $\beta$-lactoglobulin, trypsinogen, pepsin, ovalbumin, and bovine serum albumin) were run on a separate lane in every experiment in order to ascertain the molecular weights of the phosphoprotein substrates. The gels were stained with Coomassie blue to localize proteins, destained, and dried under vacuum. A linear regression analysis was conducted on the 120 molecular weight standard data points obtained from these gels and the plotted mean standard curve (Fig. 1) was found to approximate a straight line with a regression coefficient: $R^{2}=0.86$. The dried polyacrylamide gels were subjected to autoradiography using Kodak XR-OMAT x-ray film.

The stimulation of ${ }^{32} \mathrm{P}$ incorporation into individual phosphoprotein bands was quantitated by scanning of the autoradiograms on a Joyce-Loebl microdensitometer.

Cyclic AMP-stimulated phosphorylation studies. For the assay of endogenous CAMP-dependent protein kinase activity in bag cell tissues, we prepared a crude membrane fraction. Exploratory experiments with bag cell homogenates did not give consistent cyclic AMP-stimulated phosphorylation, and therefore, further experiments were restricted to the crude membrane preparation. The bag cell organs from 6 to 10 animals were dissected away from the remainder of the abdominal ganglion and the bag cell somata (and associated glia) were squeezed out from the surrounding connective tissue. This bag cell tissue then was homogenized in $50 \mathrm{mM}$ sodium acetate buffer ( $\mathrm{pH}$ 6.5) containing $10 \mathrm{~mm}$ mag. nesium chloride and $1 \mathrm{~mm}$ theophylline on ice, transferred to a polycarbonate tube at $4^{\circ} \mathrm{C}$, and centrifuged for $45 \mathrm{~min}$ at $100,000 \times \mathrm{g}$. The pellet obtained (crude membrane pellet) was resuspended in a small volume of the sodium acetate buffer described above. The phosphorylation reaction was initiated by adding $50 \mu \mathrm{l}$ of the crude membrane suspension to plastic tubes containing $70 \mu \mathrm{M}\left[\gamma^{32} \mathrm{P}\right] \mathrm{ATP}$ and the sodium salt of cyclic $3^{\prime}: 5^{\prime}-$ adenosine monophosphate at the appropriate concentration. The subsequent treatments were identical to those described above for the protein kinase catalytic subunit.

Inorganic ${ }^{32} P$ labeling studies. Whole abdominal gan- 
glia with attached pleurovisceral connective nerves were incubated at $14^{\circ} \mathrm{C}$ in $2 \mathrm{ml}$ of $(\mathrm{pH} \mathrm{7.8)}$ filtered seawater (FSW) containing $0.5 \mathrm{mCi}$ of $\mathrm{Na}_{2} \mathrm{H}^{32} \mathrm{PO}_{4}$ (New England Nuclear) for 22 to $24 \mathrm{hr}$. This incubation period was chosen because previous reports (Levitan and Barondes, 1974) indicated that shorter incubations resulted in highly variable phosphoprotein patterns. After incubation, the ganglia were removed and transferred to a recording chamber containing $2 \mathrm{~mm}$ theophylline in FSW at $14^{\circ} \mathrm{C}$. Experimental ganglia were stimulated electrically to afterdischarge by passing current $(22 \mathrm{~V}, 2.5 \mathrm{msec}$; $6 \mathrm{~Hz}, 5$ to $10 \mathrm{sec}$ ) through an extracellular suction electrode applied to the distal end of one pleuroabdominal connective nerve. Controls received no stimulation. At 2 or $20 \mathrm{~min}$ into the afterdischarge, the ganglion was removed, and the bag cell organs were dissected free and immediately homogenized with a ground glass homogenizer in $10 \%$ trichloroacetic acid on ice. The resulting precipitate was collected by centrifugation, washed twice with trichloroacetic acid, and extracted with acetone/ ethanol to remove lipids. The pellet was resuspended in $0.6 \mathrm{ml}$ of $0.2 \mathrm{M}$ sodium phosphate, $\mathrm{pH} 6.4$, containing 100 $\mu \mathrm{g} / \mathrm{ml}$ of ribonuclease A (Sigma) and incubated at $37^{\circ} \mathrm{C}$ for $2 \mathrm{hr}$. Trichloroacetic acid was added to precipitate the protein and the pellet was washed twice with $10 \%$ trichloroacetic acid, rinsed with acetone, and resuspended in sample buffer containing $10 \%$ glycerol, $2 \%$ sodium dodecyl sulfate, $5 \% \quad \beta$-mercaptoethanol, and $0.001 \%$ bromphenol blue for electrophoresis as above.

Afterdischarge-dependent phosphorylation. A second method that was used to investigate changes in the state of phosphorylation during afterdischarge was a back phosphorylation or postlabeling procedure similar to that described by Dolphin and Greengard (1981). Large animals (reproductive tract weights, 3.0 to $7.5 \mathrm{gm}$ were employed for this purpose due to the prominence of $\mathrm{BC}$ 2 protein in their bag cell tissues.

Abdominal ganglia were dissected in the recording chamber at $14^{\circ} \mathrm{C}$ to prepare hemiganglia consisting of separate right and left sides and associated bag cell clusters. The cut preparation was rinsed two or three times with fresh FSW at $14^{\circ} \mathrm{C}$ and then either the left or right bag cell cluster was afterdischarged by stimulating the pleurovisceral connective with an extracellular suction electrode $(22 \mathrm{~V}, 2.5 \mathrm{msec} ; 6 \mathrm{~Hz}, 5$ to $10 \mathrm{sec})$. The remaining cluster was employed as a control. In some experiments, bag cell clusters in whole abdominal ganglia were triggered to afterdischarge and matched ganglia from animals with similar reproductive tract weights were used for controls. At either 2 or 20 min into the afterdischarge, the experimental and control hemiganglia were removed from the recording chamber, the bag cell organs were quickly dissected free and homogenized separately in ground glass homogenizers containing $50 \mathrm{~mm}$ sodium acetate buffer ( $\mathrm{pH} 6.5$ ), $10 \mathrm{~mm}$ magnesium chloride, $1 \mathrm{~mm}$ zinc acetate, and $1 \mathrm{~mm}$ theophylline on ice. The control and experimental bag cell organ homogenates then were incubated for 1 min with 25 units of protein kinase catalytic subunit (PKC) as described above.

Quantitation by densitometry of autoradiograms. The phosphorylation changes occurring in the different experimental conditions described in this paper were quan- titated by means of microdensitometry. Densitometer scans of the autoradiograms were carried out on a JoyceLoebl microdensitometer, routinely using a 0 to 1 optical density scale. In all cases, the peak area was quantitated by cutting out and weighing the peak in question from the densitometer tracing on copy paper as described by Rudolph and Kreuger (1979). Cyclic AMP and PKC effects were quantitated directly using the peak area. In the case of tracings from prelabeled preparations, $\mathrm{BC}-1$ and $\mathrm{BC}-2$ areas were expressed as a ratio relative to the area of an internal reference peak at 28,000 daltons (see Fig. 3) that could be identified routinely in all of the preparations and did not appear to undergo a change in phosphorylation state.

In the case of the postlabeling technique, BC-1 and $\mathrm{BC}-2$ peak areas were expressed as a ratio relative to the combined areas of three routinely identifiable reference peaks at $45,000,62,000$, and 68,000 daltons (Fig. 2). The two methods of choosing internal reference peaks in preand postlabeling conditions were different because the high optical density background in the high molecular weight region of the autoradiograms resulting from the former technique made it difficult to identify the $45,000-, 62,000-$, and 68,000-dalton peaks in every preparation; therefore, the major phosphoprotein at 28,000 daltons was employed as a reference peak when prelabeling. The three higher molecular weight peaks $(45,000$, 62,000 , and 68,000) were clearly identifiable in every postlabeling preparation, whereas the 28,000-dalton phosphoprotein was only a minor phosphoprotein under these experimental conditions.

Protease digestion experiments. To establish the proteinaceous nature of the phosphorylated bands observed on the SDS-polyacrylamide gels, experiments were conducted with trypsin and pronase. Pronase (Calbiochem) at a concentration of $100 \mu \mathrm{g} / \mathrm{ml}$ and trypsin (Sigma, type XII) at a concentration of $50 \mu \mathrm{g} / \mathrm{ml}$ were incubated with crude membrane preparations prelabeled by incubation with protein kinase catalytic subunit and $\left[\gamma-{ }^{32} \mathrm{P}\right] \mathrm{ATP}$. Similar experiments were carried out on bag cell proteins prelabeled with $\mathrm{Na}_{2} \mathrm{H}^{32} \mathrm{PO}_{4}$. Controls were conducted with the same treatment using heat-inactivated enzymes.

Pulse-chase experiment. In order to demonstrate that the major phosphoprotein in bag cell tissue was not the prohormone precursor to the egg-laying hormone reported by Arch (1976), a double label experiment was conducted. Pleurovisceral ganglia were incubated for 1 $\mathrm{hr}$ at $14^{\circ} \mathrm{C}$ in artificial sea water medium (Arch, 1972) supplemented with $20 \mathrm{~mm}$ glucose and containing 0.5 $\mathrm{mCi}$ of $\left[{ }^{3} \mathrm{H}\right]$ leucine. A crude membrane fraction was prepared from the bag cell clusters as described above and then reacted with $\left[\gamma-{ }^{32} \mathrm{P}\right] \mathrm{ATP}$ and protein kinase catalytic subunit. The reaction was stopped after $1 \mathrm{~min}$ by the addition of the sample buffer described above. An SDS-10\% polyacrylamide gel was run and the gel tracks were sliced into $0.25-\mathrm{mm}$ segments with a razor blade. These segments then were counted in Wilson's cocktail (Ward et al., 1970) for ${ }^{32} \mathrm{P}$ and ${ }^{3} \mathrm{H}$ using a Beckman LS230 scintillation counter with corrections being made for count crossover.

$\mathrm{NH}_{2}$-terminal amino acid sequence analysis of protein $B C$-2. In order to characterize the bag cell-specific substrate of phosphorylation (BC-2) as fully as possible 
from the small amount of material available, we employed a new, highly sensitive protein sequenator developed at California Institute of Technology. This device is two orders of magnitude more sensitive than the next most sensitive protein sequenator in existence and allows the determination of the amino acid sequence from a single protein band excised from an SDS-polyacrylamide gel (Hewick et al., 1981). A crude membrane pellet was prepared from bag cell clusters pooled from 30 animals. This pellet was resuspended in $200 \mu \mathrm{l}$ of sample buffer heated at $90^{\circ} \mathrm{C}$ for $15 \mathrm{~min}$. Sodium thioglycolate was added to a final concentration of $5 \mathrm{~mm}$. The sample then was electrophoresed on an SDS-10\% polyacrylamide gel, followed by Coomassie blue staining. The Coomassie blue-stained BC-2 band was excised from the gel and eluted electrophoretically by the method of Hunkapiller et al. (1982): the excised gel fragments in $0.05 \mathrm{~m}$ Tris/ acetate buffer ( $\mathrm{pH} 7.8$ ) containing $0.01 \%$ SDS were placed in an apparatus for the electrophoresis $(60 \mathrm{~V}, 16 \mathrm{hr})$ of the protein into a collection tube capped with a disc of Spectrapor dialysis membrane (Spectrum Medical Industries, CA; 6,000 - to 8,000 -dalton cutoff). The $200 \mu \mathrm{l}$ of sample concentrate was salt-exchanged by electrodialysis ( $50 \mathrm{~V}, 8 \mathrm{hr}$ ) against $0.05 \mathrm{M}$ ammonium bicarbonate containing 0.1\% SDS (Hunkapiller et al., 1982). An aliquot of the eluted sample was run on an SDS-12\% polyacrylamide gel and stained with Coomassie blue to ascertain purity. A single band was observed with an approximate molecular weight of 20,000 to 22,000 . An aliquot of the eluted protein was divided into two samples, one of which was hydrolyzed, the other was untreated, and these then were subjected to amino acid analysis (Smyth et al., 1963) on a Durrum D500 amino acid analyzer. Fifty microliters of the eluted sample was loaded into the cartridge of the new highly sensitive gas-liquid solid phase sequenator developed at California Institute of Technology (Hewick et al., 1981) and sequenced for 22 cycles. We estimate (based on amino acid analysis) that the sample used for sequencing contained approximately $100 \mathrm{pmol}$ of protein.

\section{Results}

Afterdischarge-dependent phosphorylation. When bag cells are stimulated to afterdischarge in FSW at $14^{\circ} \mathrm{C}$, there is a significant change in the phosphorylation of two proteins, $\mathrm{BC}-1$ and $\mathrm{BC}-2$. One of these, $\mathrm{BC}-2$, a protein with a molecular weight of $20,600( \pm 400)$, undergoes a significant increase in phosphorylation with both pre- and postlabeling techniques. The range of molecular weights determined for phosphoprotein $\mathrm{BC}-2$ from 24 separate SDS-10\% polyacrylamide gels determined from experiments over a 2 -year period was 18,500 to 24,000 .

This afterdischarge-dependent phosphorylation change was seen as a $73 \%( \pm 9 \%)$ decrease in the phosphorylation of the $\mathrm{BC}-2$ protein substrate in bag cell organ homogenates from abdominal ganglia allowed to afterdischarge for $20 \mathrm{~min}$ when back-phosphorylated with protein kinase catalytic subunit. No change in phosphorylation of the minor phosphoprotein band BC-1 was detected in these experiments. The result from a single hemiganglion experiment is shown in Figure 2. The change in the phosphorylation state of BC-2 with afterdischarge was significant ( $p<0.05 ; N=4$ ) with a paired

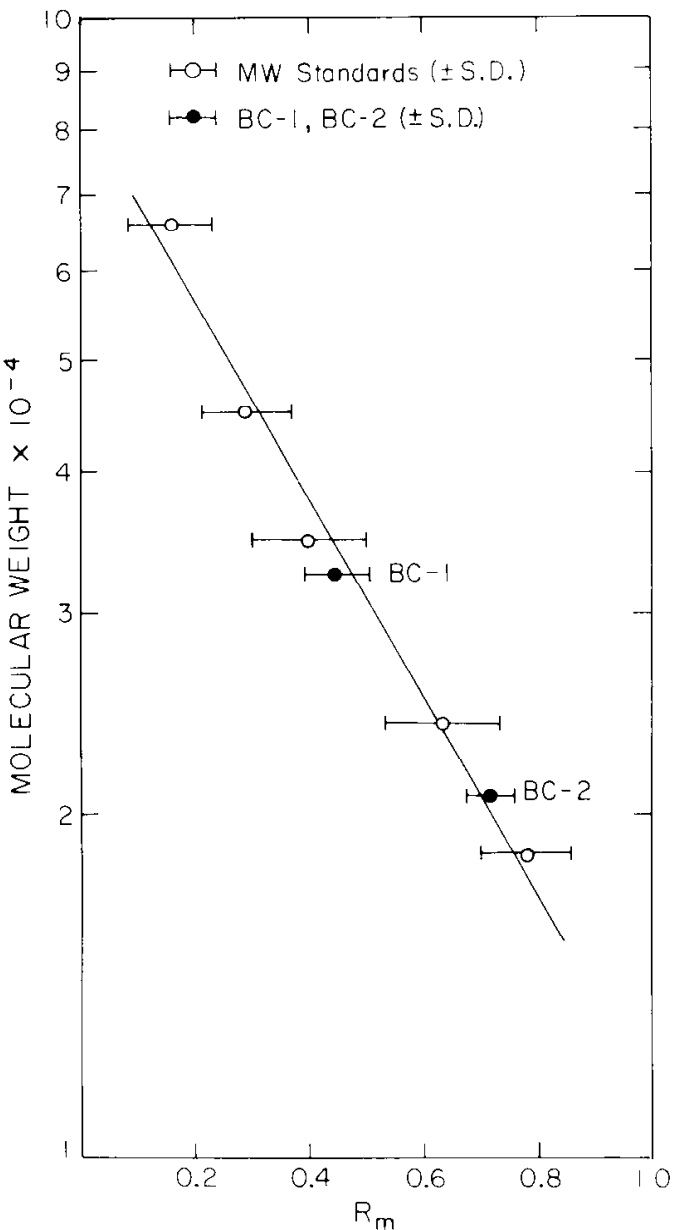

Figure 1. Averaged molecular weight standard curve. The abscissa represents the relative mobility $\left(R_{m}\right)$ of the protein band relative to the gel front. The ordinate shows the molecular weight. The molecular weight standard curve represents the mean values $( \pm S D)$ of the mobility of the molecular weight $(M W)$ markers ( $\beta$-lactoglobulin, trypsinogen, pepsin, ovalbumin, and bovine serum albumin) from 24 separate SDS-10\% polyacrylamide gels run over a 2-year period. The plotted straight line represents the best fit linear regression to this data $\left(R^{2}=0.86\right)$. The mean molecular weights obtained for $\mathrm{BC}$ 1 and $\mathrm{BC}-2$ were calculated from their relative mobilities on the same 24 polyacrylamide gels as the standard curve. (BC-1 represents the mean calculated from the 21 polyacrylamide gels on which it was visible.)

$t$ test analysis. There was no difference in the density of the Coomassie blue-stained $\mathrm{BC}-2$ protein band from the afterdischarged and control bag cell organs upon visual inspection. In two cases out of four, a change in the phosphorylation of a protein running near the front (approximately 12,000 to 14,000 daltons) also was observed (see Fig. 2). These back phosphorylation labeling studies conducted with exogenous protein kinase indicate that BC-2 undergoes a substantial increase in phosphorylation during afterdischarge, and consequently, there are fewer sites available for phosphorylation upon incubation with radiolabeled ATP. Experiments also were conducted at a time point 2 min into the afterdischarge, when cyclic AMP concentrations are known to peak (Kaczmarek et al., 1978), but no detectable change in phosphorylation of any of the bands was observed $(N=4)$. There was no 


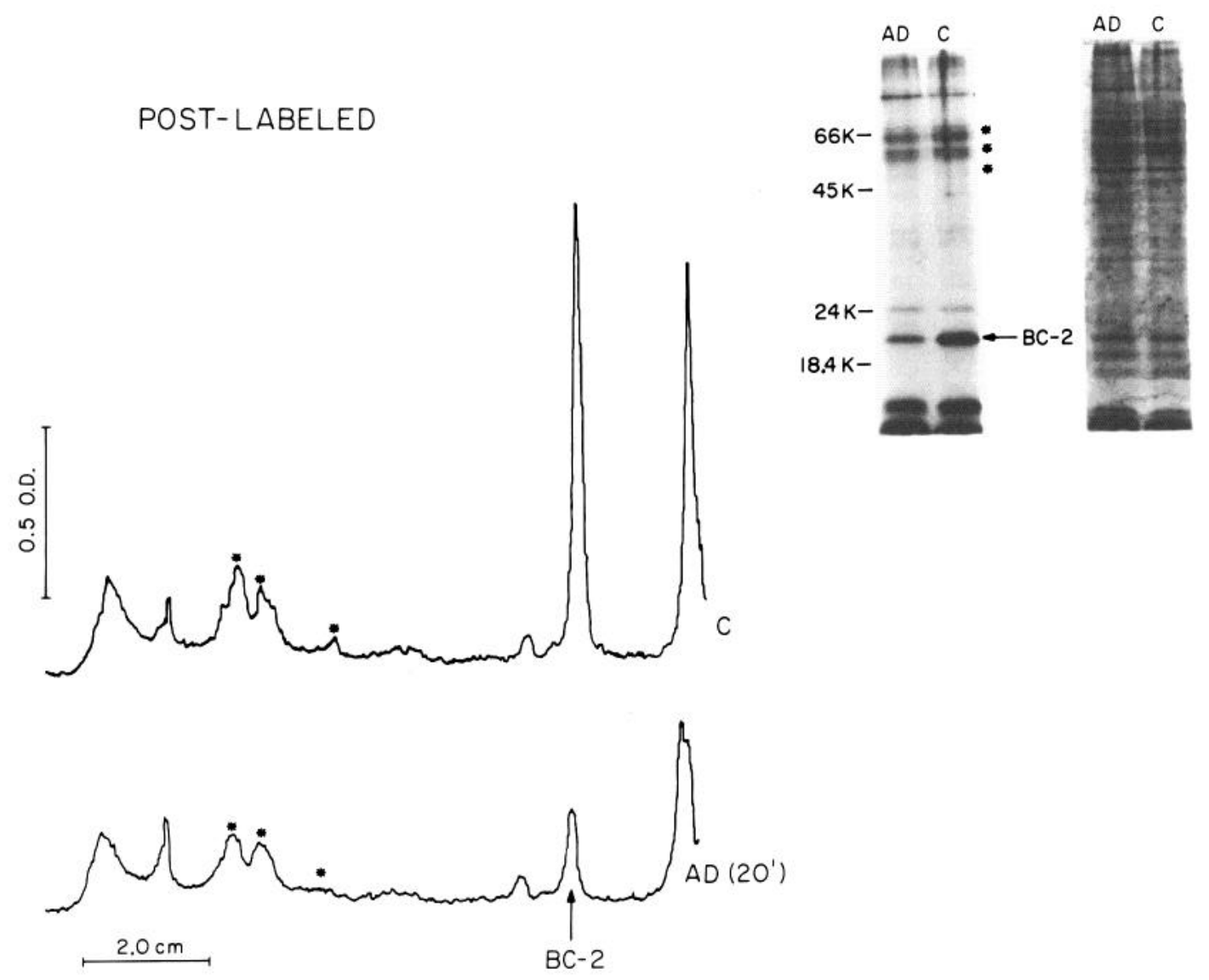

Figure 2. Afterdischarge-dependent phosphorylation: postlabeled preparation. The hemiganglion preparation where the left bag cell cluster was stimulated electrically to afterdischarge and then dissected at 20 min into the afterdischarge and "backphosphorylated" with protein kinase is shown. The densitometer traces shown illustrate the change in phosphorylation of BC-2 with afterdischarge $(A D)$ compared with the control $(C)$ from the undischarged cluster. The inset photograph shows the autoradiogram (left two tracks) from which the densitometer traces were made and the corresponding Coomassie blue proteinstained gel (right two tracks). The three reference phosphoprotein bands used in quantitating the changes in BC-2 (see "Materials and Methods") are denoted by asterisks. O.D., optical density.

significant change in phosphorylation of $\mathrm{BC}-2$ at this time point $(25 \pm 17 \%$ increase $)$.

Experiments also were conducted with whole abdominal ganglia prelabeled for 22 to $24 \mathrm{hr}$ with inorganic ${ }^{32} \mathrm{P}$. The pattern of phosphoproteins of bag cell organs labeled in this manner was similar, but not identical, to that obtained under in vitro labeling conditions with protein kinase. Bag cell organs prelabeled in this manner were stimulated electrically to afterdischarge and dissected at time points of 2 and 20 min into the afterdischarge, and their protein phosphorylation patterns were compared to unstimulated controls. The two phosphoproteins that appeared to undergo reproducible changes in phosphorylation were a 33,000 -dalton $(32,500 \pm 600)$ and the $\mathrm{BC}$ 2 protein (Fig. 3). The 33,000-dalton band (BC-1) increased in phosphorylation by $82 \%(p<0.005)$ at $2 \mathrm{~min}$ into the afterdischarge and it appeared to remain elevated at $20 \mathrm{~min}$ (Table I). The BC-2 protein was observed to undergo a change $(92 \% ; p<0.025)$ in phosphorylation at $20 \mathrm{~min}$ into the afterdischarge, but no significant change at the 2-min time point. A control band of 45,000 daltons analyzed in a similar manner did not undergo a significant change in phosphorylation at either time point (Table I). High molecular weight $(>100,000)$ phosphoproteins were difficult to quantitate as a result of the often intense but diffuse labeling of these bands with long ${ }^{32} \mathrm{P}$-prelabeling incubation periods.

Protein kinase catalytic subunit-stimulated phosphorylation. In a series of five separate experiments, the effect of exogenously added protein kinase catalytic subunit on the phosphorylation of bag cell proteins in a homogenate of bag cell organs was studied (Fig. 4). All of the major labeled bands were found to be trypsin- and pronase-sensitive. The three protein substrates showing the greatest increase in phosphorylation (as quantitated by an increase in the densitometric area of individual peaks of an autoradiogram) were the BC-1, BC-2, and 100,000 -dalton bands. We repeated this procedure for the other regions of the nervous system and found that the 100,000-dalton phosphoprotein occurs in the connective tissue surrounding the cluster but not in the bag cell tissues (Table II). This phosphoprotein may be the 100,000-dalton paramyosin described in Aplysia muscle (Mandelbaum, 1980). The BC-2 substrate is a major band both on gels stained for protein with Coomassie blue and on autoradiograms showing the basal phosphorylation state. The regional distribution of this band (Table II) shows that it is found within the bag cell cluster as well as the pleurovisceral connective nerve where bag cell processes extend and appears to be relatively specific to 


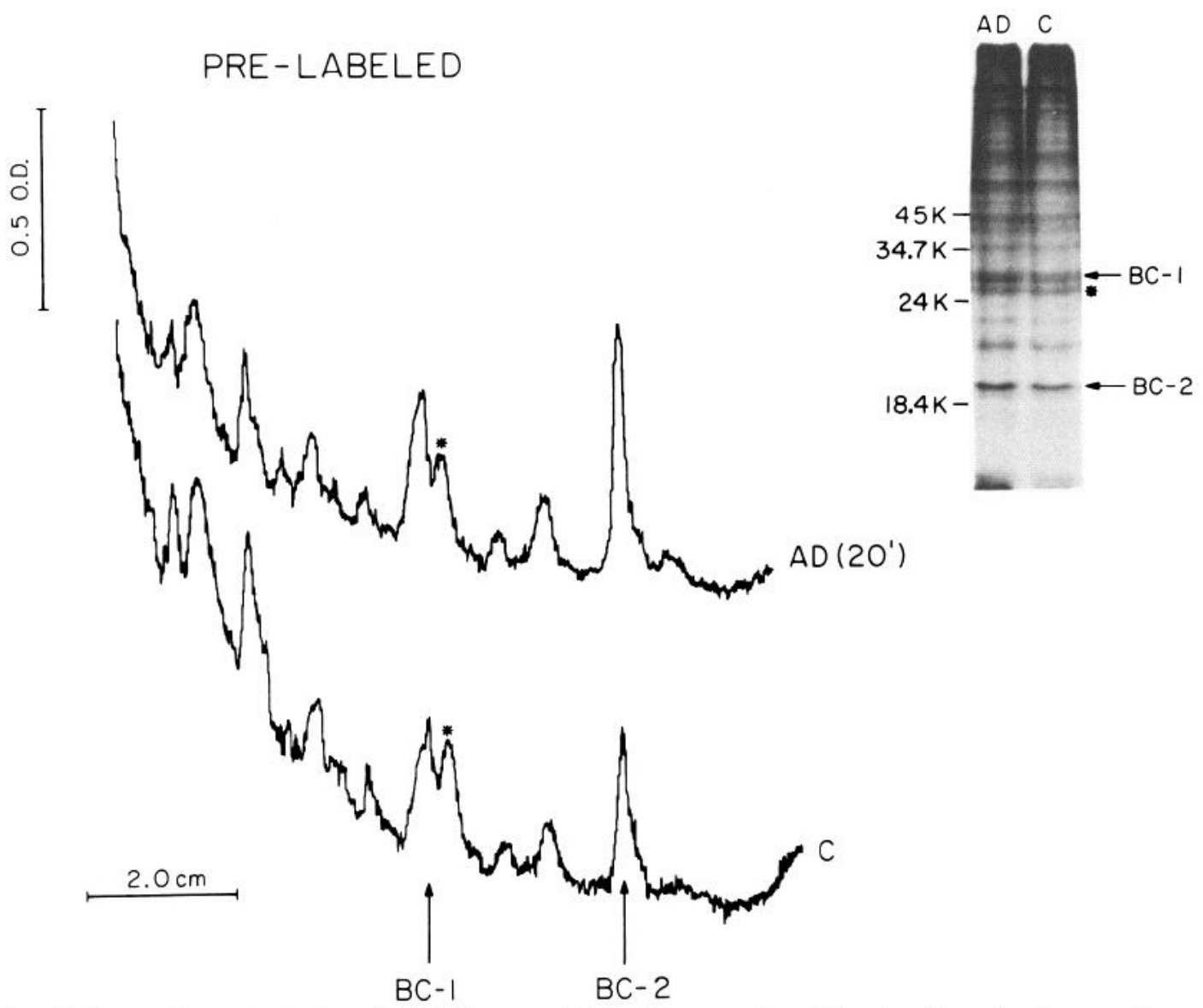

Figure 3. Afterdischarge-dependent phosphorylation: prelabeled preparation. The densitometer traces shown illustrate the change in phosphorylation of $\mathrm{BC}-1$ and $\mathrm{BC}-2$ with afterdischarge $(A D)$ compared with the undischarged control $(C)$ in abdominal ganglia prelabeled with ${ }^{32} \mathrm{P}$ as $\mathrm{Na}_{2} \mathrm{H}^{32} \mathrm{PO}_{4}$ for 22 to $24 \mathrm{hr}$. The inset photograph shows the autoradiogram from which the densitometer traces were made. An asterisk is used to denote the reference peak (see "Materials and Methods") employed to quantitate the changes in BC-1 and BC-2. O.D., optical density.

\section{TABLE I}

Results of a study of phosphorylation changes during afterdischarge of phosphoproteins prelabeled for 22 to $24 \mathrm{hr}$ with inorganic ${ }^{32} \mathrm{P}$

Data are plotted as the percentage of change $( \pm S E M)$ in the area under the peak on a densitometer scan relative to a 28,000 -dalton reference peak observed not to change with afterdischarge. The number of separate experiments is shown in parentheses. The $\mathrm{BC}-1$ and $\mathrm{BC}-2$ phosphoproteins were observed to undergo significant increases in phosphorylation during afterdischarge. The 45,000-dalton phosphoprotein is included as a representative phosphoprotein that did not undergo a change in phosphorylation during afterdischarge. Statistical significance was calculated using a one-tailed paired $t$ test.

\begin{tabular}{cccc}
\hline \multirow{2}{*}{ Protein $\left(M_{r}\right)$} & \multicolumn{3}{c}{ Phosphorylation Change } \\
\cline { 2 - 4 } & \multicolumn{2}{c}{2 min } & 20 min \\
\hline & & \\
BC-2 & $-19 \pm 28 \quad(5)$ & $92 \pm 23^{a}(4)$ \\
BC-1 & $82 \pm 14^{b}(8)$ & $69 \pm 43^{c}(4)$ \\
45,000 & $-11 \pm 12 \quad(8)$ & $-9 \pm 32 \quad(4)$ \\
\hline
\end{tabular}

\footnotetext{
${ }^{a} p<0.02$.
}

${ }^{b} p<0.005$.

${ }^{\prime} p<0.05$.

these tissues. Treatment with $\mathrm{PKC}$ results in a significant increase in the phosphorylation of this band on autoradiograms relative to other major bands, such as the 62,000 - and 68,000 -dalton bands. The BC-1 phosphoprotein is a minor band on both protein-stained gels and
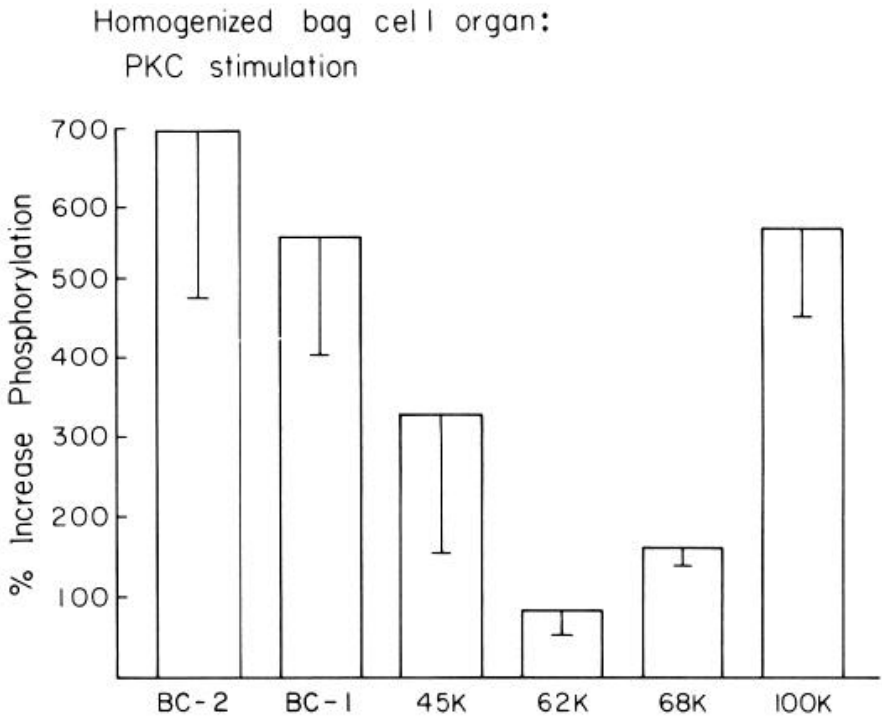

Figure 4. Protein kinase catalytic subunit stimulation of protein phosphorylation: the increase in area under the peak on a densitometer scan of the autoradiogram. The histogram represents the data from five separate experiments $( \pm \mathrm{SEM})$.

autoradiograms of the basal phosphorylation state in bag cell organs but undergoes a substantial increase in phosphorylation upon treatment with PKC. The increase was difficult to quantitate due to the very small amount of 
phosphorylation observed in this band under basal conditions (Fig. 5).

Cyclic AMP-stimulated phosphorylation. In a study $(N=7)$ of endogenous cyclic AMP-stimulated protein kinase in crude membrane preparations from bag cell

\section{TABLE II}

Distribution of phosphoproteins in CNS

Homogenates were prepared of each of the regions of the Aplysia nervous system and phosphorylated with $\left[\gamma^{32} \mathrm{P}\right] \mathrm{ATP}$ and the catalytic subunit of protein kinase as described under "Materials and Methods." Bag cell organs consisted of the bag cell cluster and surrounding connective tissue, including axons of passage in the underlying connective nerve. Isolated bag cell clusters consisted of bag cell somata separated from the surrounding connective tissue. The other head ganglia were prepared from ganglion homogenates separated from surrounding connective tissues. The approximate amount of the phosphoprotein detected in autoradiograms is denoted by the number of "+" symbols; a "-" indicates that the band could not be detected.

\begin{tabular}{cccccc}
\hline$M_{r}$ & $\begin{array}{c}\text { Isolated } \\
\text { Bag Cell } \\
\text { Cluster }\end{array}$ & $\begin{array}{c}\text { Bag Cell } \\
\text { Organ }\end{array}$ & $\begin{array}{c}\text { Pleuro- } \\
\text { visceral } \\
\text { Connective }\end{array}$ & $\begin{array}{c}\text { Pleural- } \\
\text { Pedal } \\
\text { Ganglia }\end{array}$ & $\begin{array}{c}\text { Cerebral } \\
\text { Ganglion }\end{array}$ \\
\hline 122,000 & & + & + & + & + \\
100,000 & - & ++ & ++ & - & - \\
68,000 & + & +++ & +++ & +++ & + \\
62,000 & ++ & +++ & +++ & +++ & + \\
45,000 & + & + & + & + & \\
BC-1 & + & + & + & + & - \\
BC-2 & +++ & ++ & + & - & - \\
\hline
\end{tabular}

"Connective tissue removed. tissues, a cyclic AMP dose-dependent increase in the phosphorylation of all of the major bands was observed (Figs. 5 and 6). The phosphoproteins undergoing the greatest increase in phosphorylation were the $\mathrm{BC}-2$ and 68,000 -dalton bands. As shown in Table II, the 68,000 dalton phosphoprotein is widely distributed throughout the nervous system and is not enriched in bag cells. Moreover, recent studies of the regional distribution of phosphoproteins show that the 68,000 -dalton substrate is not found in the connective tissue sheath of the pleuroabdominal connective nerve but is enriched in the nerve trunk (K. R. Jennings, L. K. Kaczmarek, and F. Strumwasser, unpublished observations). This phosphoprotein may be the one described earlier in pleurovisceral connective nerve by Ram and Ehrlich (1978). The BC-1 protein appeared to undergo the smallest cyclic AMPstimulated phosphorylation change observed although the magnitude of this change was difficult to quantitate for the reasons mentioned above.

The protein phosphorylation reaction also was conducted in a sodium acetate buffer medium containing 1 mM EGTA in the presence or absence of $4 \mathrm{~mm}$ calcium chloride. Calcium was found to inhibit both basal and cAMP-stimulated protein phosphorylation activity, a finding that also has been reported in other systems (Lemay et al., 1974). Cyclic AMP-stimulated phosphorylation was inhibited by more than $50 \%$ under these conditions. EGTA alone enhanced the phosphorylation rate over controls lacking EGTA. Under the reaction

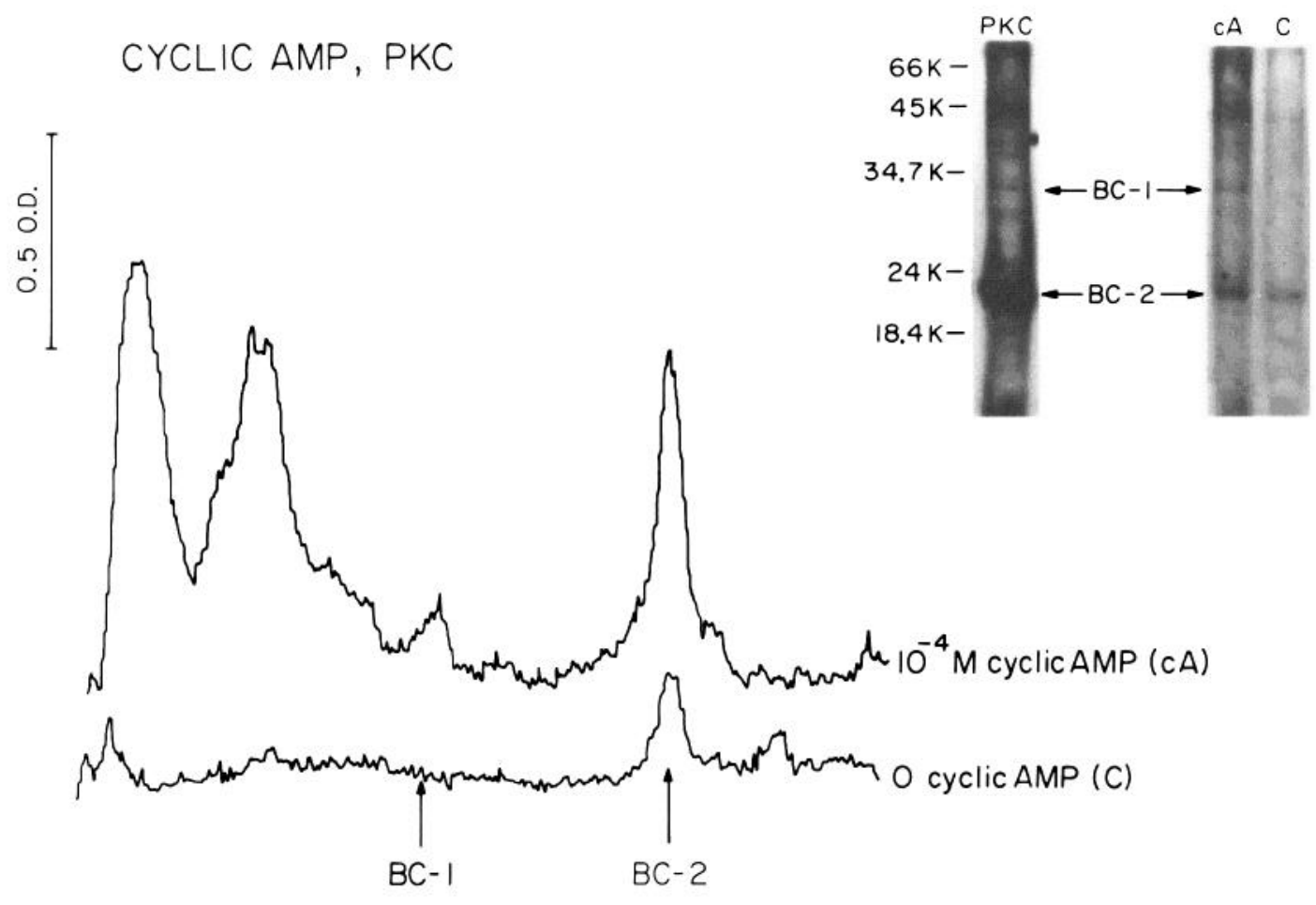

$2.0 \mathrm{~cm}$

Figure 5. Cyclic AMP- and protein kinase-stimulated phosphorylation. The densitometer traces show the increase in phosphorylation with $10^{-4} \mathrm{M}$ cyclic AMP of proteins in a crude membrane preparation of bag cell tissues. The inset photograph shows the autoradiogram from which the densitometer traces were made. In addition, the leftmost track shows the effect of a high concentration (50 to 100 units) of protein kinase catalytic subunit on the phosphorylation of these substrate proteins on the same gel. O.D., optical density. 


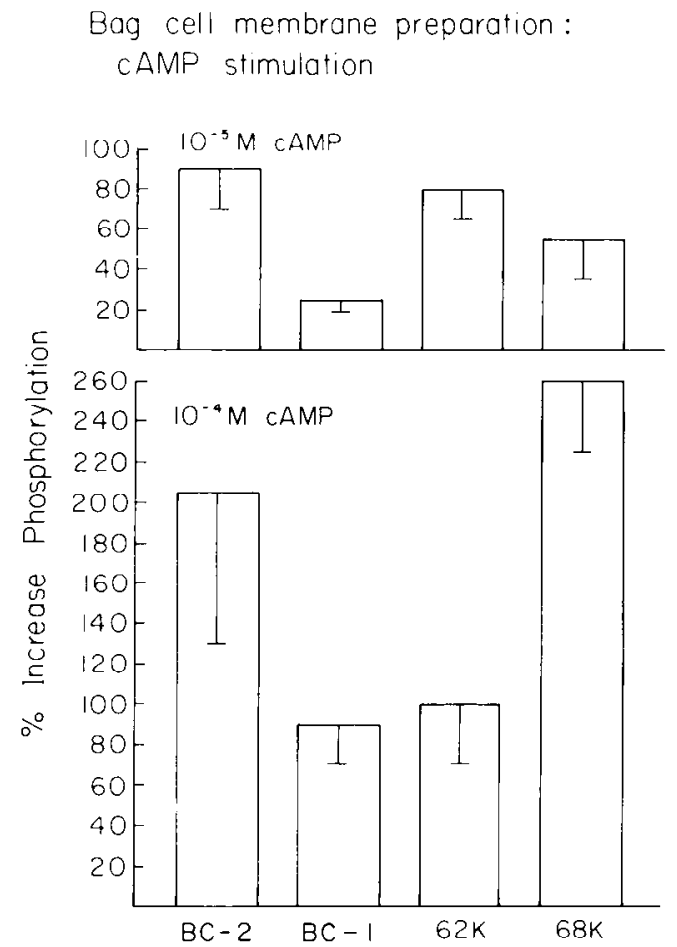

Figure 6. Cyclic AMP stimulation of protein phosphorylation in bag cell membrane preparations. The percentage of increase in phosphorylation represents the increase in the area under the peak in a densitometer scan of the autoradiogram. The histogram represents the data from seven separate experiments $( \pm$ SEM).

conditions used to study the kinase activity in bag cell tissues, it may be that the endogenous calcium ion inhibits the observed basal phosphorylation rate.

Characterization of the $B C-2$ protein. The $\mathrm{BC}-2$ protein, which we have shown to undergo a significant increase in phosphorylation during afterdischarge and which is the major substrate for both endogenous and exogenous protein kinase in bag cell tissues was characterized further. As noted above, it was detectable as a distinct phosphoprotein on autoradiograms prepared from pleuroabdominal connective nerves and bag cell clusters but not pleural-pedal or cerebral ganglia (Table II). An SDS-polyacrylamide gel was run with bag cell tissues labeled by the two methods $\left(\left[\gamma^{3.2} \mathrm{P}\right] \mathrm{ATP}\right.$ and ${ }^{32} \mathrm{P}$ as sodium orthophosphate) and the bands identifiable as $\mathrm{BC}-1$ and $\mathrm{BC}-2$ appeared to run with identical electrophoretic mobilities under both labeling schemes.

In order to demonstrate that BC-2 was not identical to the 29,000-dalton egg-laying hormone (ELH) precursor earlicr reported by Arch (1976), double label experiments were conducted using $\left[{ }^{3} \mathrm{H}\right]$ leucine to follow newly synthesized protein. The ${ }^{32} \mathrm{P}$-labeled phosphoprotein migrated faster and ran separately from the ${ }^{3} \mathrm{H}$-labeled protein described as pro-ELH by Arch (Fig. $7 B$ ).

The BC-2 protein was isolated from an SDS-polyacrylamide gel and analyzed on a gas-liquid solid phase sequenator as described under "Materials and Methods." A partial sequence of the first 23 residues of the $\mathrm{NH}_{2^{-}}$ terminal region of $100 \mathrm{pmol}$ of the protein was obtained (Fig. 7A). This analysis was repeated on a second, inde- pendently isolated BC-2 band, confirming this partial sequence. This region seems to be hydrophobic in character. The protein sample also was subjected to amino acid analysis twice and the amino acid compositions from each run are shown in Table III. Much less sample was available for the second amino acid analysis (run 2), and therefore, the values obtained are less reliable. The data from the two runs were not averaged but are shown separately in Table III. A computer search was conducted to determine if the partial sequence obtained was similar to that found in any previously described proteins. There was no significant homology between the partial sequence of the first 23 residues of this protein and any of the 1,612 sequenced proteins examined in the search.

\section{Discussion}

Cyclic AMP-stimulated phosphorylation is brought about by the action of the tetrameric enzyme, cyclic AMP-dependent protein kinase (Rubin and Rosen, 1975). On binding cyclic AMP to the two regulatory subunits, the tetramer dissociates, releasing the two catalytic subunits which then transfer the terminal phosphate of ATP to serine and threonine residues of substrate proteins. Many tissues in diverse organisms have been shown to possess this enzyme (Greengard, 1978). Of particular interest to the neurobiologist are those systems where protein kinase action is thought to bring about a change in the state of membrane excitability.

A number of neural systems, both invertebrate (Paris et al., 1980; Neary et al., 1980) and vertebrate (Browning et al., 1979; Greengard, 1978), have been investigated in an attempt to address the role of protein phosphorylation in membrane excitability. One of the major difficulties in studying neural systems such as these is the heterogeneity of the cellular population under investigation. Nonneural preparations, such as the turkey erythrocyte (Greengard, 1978) and cultured adrenal medulla cells (Amy and Kirshner, 1981), have provided relatively homogeneous populations of cells for the study of the relationship between phosphorylated proteins and their putative functions, such as ion flux and secretion. The bag cells of Aplysia represent a neural system where the cellular homogeneity makes it particularly suitable for the study of biochemical events and their relationship to membrane excitability (Strumwasser et al., 1981). All neurons in the bag cell cluster are coupled electrically by means of gap junctions (Kaczmarek et al., 1979) and afterdischarge synchronously in response to brief electrical stimulation. We have presented previously biochemical and electrophysiological evidence for a role of cyclic AMP in the excitability changes during afterdischarge.

In this paper, we have investigated protein phosphorylation in the bag cell neurons and its relationship to afterdischarge. We have demonstrated that cyclic AMP can act on an endogenous kinase in bag cell tissue to stimulate the phosphorylation of specific proteins. Two proteins were shown to undergo significant changes in the phosphorylation state associated with afterdischarge. The regional distribution of all of the major phosphoproteins found in bag cell tissues was investigated and only BC-2 appeared to be relatively specific to bag cell tissues (Table II). This protein was the major substrate for both 
A.

$$
\begin{gathered}
H_{2} N-()-(\quad)-V a l-H i s-G l y-L y s-A s n-P h e-A l a-(A r g) \\
-A s n-(A r g)-A l a-V a l-L y s-()-()-()-(\quad)-\text { Phe }
\end{gathered}
$$$$
\text { Val }- \text { Val }-(\text { Leu }) \ldots . . . .
$$

B.

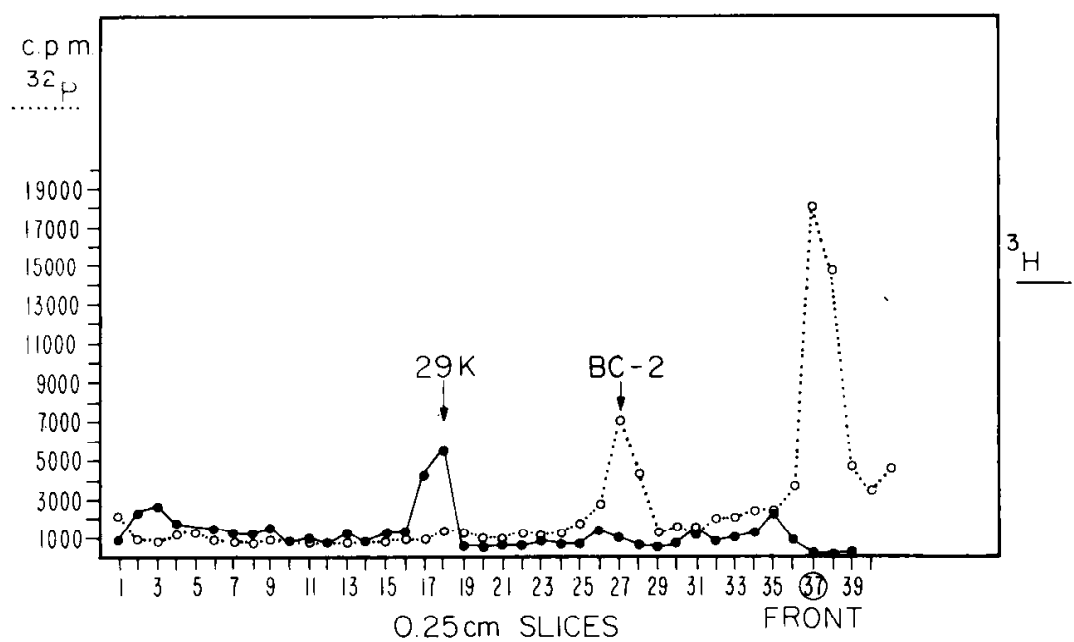

Figure 7. Characterization of the BC-2 protein. A, Amino acid sequence of the BC-2 phosphoprotein isolated from crude membrane preparations of bag cell tissues. The data presented are the result of two separate experiments. $B$, Pulse-chase experiment with $\left[{ }^{3} \mathrm{H}\right]$ leucine labeling of the precursor to ELH. The radioactivity profile obtained on a SDS-10\% polyacrylamide gel by sectioning is illustrated. The solid line shows the ${ }^{3} \mathrm{H}$ counts obtained; the dotted line shows the counts due to ${ }^{32} \mathrm{P}$ label. The approximate molecular weights (based on molecular weight standards) of the two labeled proteins are shown. The data shown represent one of three separate experiments with similar results.

cyclic AMP-stimulated phosphorylation and phosphorylation stimulated by added catalytic subunit of cyclic AMP-dependent protein kinase. Whether the change in phosphorylation state which occurs in this protein during afterdischarge is a direct consequence of the increase in cyclic AMP levels during afterdischarge (Kaczmarek et al., 1978) cannot, however, be determined at present. Although a protein may serve as a substrate for cyclic AMP-dependent protein kinase in vitro, this does not ensure that its phosphorylation in vivo is solely under the control of this enzyme. Other mechanisms, such as calcium-dependent phosphorylation, may be the primary regulators of the phosphorylation state for a particular protein (Schulman and Greengard, 1978a, b). It is possible that the BC-2 protein, which did not undergo an increase in phosphorylation at $2 \mathrm{~min}$ into the afterdischarge (when cyclic AMP levels peak), may undergo a later $\mathrm{Ca}^{2+}$-dependent phosphorylation. In the bag cell studies reported here, we found that exogenous calcium did alter phosphorylation in cell-free preparations in vitro. Studies are planned to investigate this phenomenon in more detail.

Under both of the labeling paradigms that we have used, prolonged prelabeling with ortho $\left[{ }^{32} \mathrm{P}\right]$ phosphate and rapid "back phosphorylation" with PKC, we ob- served a phosphoprotein with an apparent molecular weight of 33,000 (BC-1). Although the former method showed the phosphorylation state to alter at the onset of afterdischarge, no change in phosphorylation could be detected using the latter method. The small amount of phosphorylation of the $\mathrm{BC}-1$ band in a homogenate of bag cell tissues under basal conditions may account for the difficulty of quantitating this change with the back phosphorylation technique.

The bag cell neurons undergo a number of characteristic changes in excitability following brief electrical stimulation. The onset of afterdischarge is composed of a 1to 2-min bout of high frequency firing followed by a prolonged period of lower frequency firing of broad action potentials with a predominant calcium component (Strumwasser et al., 1981; Acosta-Urquidi and Dudek, 1981). Upon cessation of afterdischarge, these neurons remain refractory for a period of many hours (Kupfermann and Kandel, 1970). The extracellular application of cyclic AMP analogues can trigger this complete sequence without electrical stimulation (Kaczmarek et al., 1978). The fact that BC-2 undergoes a large change in phosphorylation at 20 min into the afterdischarge but no significant change at 2 min suggests that it may be associated with one of the later phases of afterdischarge. It will be 
TABLE III

Amino acid composition of the $B C \cdot 2$ protein

The data shown in this table were calculated by subtracting the values obtained for the unhydrolyzed sample from the hydrolyzed sample. Run 1 shows the amino acid composition data from the aliquot that also was subjected to protein sequencing (see Fig. $7 A$ ). Run 2 shows the composition data obtained from a separate sample containing much less material.

\begin{tabular}{lrrlll}
\hline & Run 1 & Run 2 & & Run 1 & Run 2 \\
\hline & \multicolumn{2}{c}{ mol/100 } & mol & & \multicolumn{2}{c}{ mol/100 } & mol \\
Asx & 13.20 & 11.82 & Met & 0.69 & 0.95 \\
Thr & 1.80 & $3.43^{\prime \prime}$ & Ile & 2.80 & 4.28 \\
Ser & 2.76 & $4.20^{\prime \prime}$ & Leu & 7.64 & 9.20 \\
Glx & 11.48 & $13.04^{\prime \prime}$ & Phe & 4.68 & 4.53 \\
Pro & 4.92 & 4.24 & Tyr & 2.08 & 0.91 \\
Gly & 9.52 & n.d. & His & 2.12 & 3.09 \\
Ala & 11.52 & 10.29 & Lys & 6.76 & 6.04 \\
Val & 8.20 & 7.59 & Arg & 9.52 & 5.37 \\
& & & Cys & n.d. & n.d. \\
\hline
\end{tabular}

"These values are anomalously high in run 2 due to the presence of substantial contamination by these residues in the unhydrolyzed protein sample (see "Materials and Methods")

${ }^{b}$ n.d., not determined.

interesting to determine the complete time course of phosphorylation changes for both the $\mathrm{BC}-1$ and $\mathrm{BC}-2$ proteins.

Whether these proteins that we have studied are indeed substrates for the electrical changes induced by cAMP and protein kinase in bag cells cannot be determined at present. They also could be involved in a host of other cellular functions, including peptide processing, intermediary metabolism, or secretory function, although we have shown that $\mathrm{BC}-2$ is not the precursor to $\mathrm{ELH}$ previously described (Arch, 1976; Loh et al., 1977). That the BC-2 protein is not a secreted one is suggested by the fact that there is no apparent change in the density of the Coomassie blue protein staining of the band on polyacrylamide gels of bag cell clusters made to afterdischarge.

In testing the hypothesis that a cyclic AMP-dependent phosphorylation of protein controls the excitability of bag cell neurons, we have shown previously that microinjection of the catalytic subunit of cyclic AMP-dependent protein kinase into individual bag cells enhances their calcium action potentials in a manner consistent with a decrease in membrane conductance to potassium ions (Kaczmarek et al., 1980; Kaczmarek and Strumwasser, 1981a). Similar results have been reported for the enhancement of spike duration in sensory neurons initially primed with tetraethylammonium chloride in Aplysia (Castellucci et al., 1980). We have demonstrated a parallel increase in both cyclic AMP levels and intracellularly recorded spike broadening during afterdischarge in the intact bag cell clusters (Strumwasser et al., 1981). Recent studies (Kaczmarek and Strumwasser, 1981b) on voltage-clamped individual bag cell neurons in culture suggest that cyclic AMP acts by decreasing a calciumdependent potassium conductance. It may be, therefore, that one of the two phosphorylation substrates reported in this paper (BC-1 or BC-2) is linked functionally to a potassium conductance and may play a role in spike broadening and enhancement of calcium influx. It is therefore of interest that Alkon and colleagues (Alkon, 1980; Neary et al., 1980) have characterized a long lasting depolarization in type B photoreceptors of the mollusc, Hermissenda, associated with behavioral conditioning. They attribute this depolarization to a decrease in potassium conductance and find that it correlates with a change in the phosphorylation of two proteins with molecular weights of 20,000 and 23,000 . In view of the similar electrical changes in these cells and in bag cells, it will be important to determine if these phosphoproteins are related to the approximately 21,000 -dalton protein that we observe in bag cells. The sequence data presented in this paper may make such a comparison possible.

BC-2 also could be related to the 22,000 -dalton protein phospholamban that has been found in cardiac sarcoplasmic reticulum (Tada et al., 1975). Phospholamban appears to play a role in the control of intracellular calcium ion concentrations by altering the activity of $\mathrm{Ca}^{2+}$-ATPase. Control of intracellular calcium would be expected to be very important during bag cell afterdischarge and could influence the potassium conductance indirectly through calcium-activated potassium channels (Meech, 1972).

We have met many of the requirements that are needed to demonstrate that protein phosphorylation mediated by cyclic AMP influences the electrical properties of the bag cell neurons (Kaczmarek et al., 1980). It remains to be determined which phosphoproteins are related causally to the electrical events of afterdischarge and subsequent refractoriness and whether these substrates are uniquely distributed among different classes of neurons.

\section{References}

Acosta-Urquidi, J., and F. E. Dudek (1981) Soma spike of neuroendocrine bag cells of Aplysia californica. J. Neurobiol. 12: 367-378.

Alkon, D. L. (1980) Cellular analysis of a gastropod (Hermis. senda crassicornis) model of associative learning. Biol. Bull. 159: 505-560.

Amy, C. M., and N. Kirshner (1981) Phosphorylation of adrenal medulla cell proteins in conjunction with stimulation of catecholamine secretion. J. Neurochem. 36: 847-854.

Arch, S. (1972) Polypeptide secretion from the isolated parietovisceral ganglion of Aplysia californica. J. Gen. Physiol. 59: 47-59.

Arch, S. (1976) Neuroendocrine regulation of egg-laying in Aplysia californica. Am. Zool. 16: 167-175.

Browning, M., T. Dunwiddie, W. Bennett, W. Gispen, and G. Lynch (1979) Synaptic phosphoproteins: Specific changes after repetitive stimulation of the hippocampal slice. Science 203: 60-62.

Castellucci, V. F., E. R. Kandel, J. H. Schwartz, F. D. Wilson, A. U. Nairn, and P. Greengard (1980) Intracellular injection of the catalytic subunit of cyclic AMP-dependent protein kinase simulates facilitation of transmitter release underlying behavioral sensitization in Aplysia. Proc. Natl. Acad. Sci. U. S. A. 77: 7492-7496

Dolphin, A. C., and P. Greengard (1981) Serotonin stimulates phosphorylation of Protein I in the facial motor nucleus of the rat brain. Nature 289: $76-79$.

Greengard, P. (1978) Cyclic Nucleotides, Phosphorylated Proteins and Neuronal Function, Raven Press, New York.

Hewick, R. M., M. W. Hunkapiller, L. E. Hood, and W. J. Dreyer (1981) A gas-liquid solid phase peptide and protein 
sequencer. J. Biol. Chem. 256: 7990-7997.

Hunkapiller, M. W., E. Lujan, F. Ostrander, and L. E. Hood (1982) Isolation of microgram quantities of proteins from polyacrylamide gels for amino-acid sequence analysis. Methods Enzymol., in press.

Kaczmarek, L. K, and F. Strumwasser (1980) Subthreshold oscillations underlie the cAMP-induced discharge of Aplysia peptidergic neurons. Soc. Neurosci. Abstr. 6: 214.

Kaczmarek, L. K., and F. Strumwasser (1981a) The expression of long lasting afterdischarge by isolated Aplysia bag cell neurons. J. Neurosci. 1: 626-634.

Kaczmarek, L. K., and F. Strumwasser (1981b) Net outward currents of bag cell neurons are diminished by a cyclic AMP analogue. Soc. Neurosci. Abstr. 7: 932.

Kaczmarek, L. K., K. R. Jennings, and F. Strumwasser (1978) Neurotransmitter modulation, phosphodiesterase inhibitor effects, and cyclic AMP correlates of afterdischarge in peptidergic neurites. Proc. Natl. Acad. Sci. U. S. A. 75: 5200-5204.

Kaczmarek, L. K., M. Finbow, J. P. Revel, and F. Strumwasser (1979) The morphology and coupling of Aplysia bag cells within the abdominal ganglion and in cell culture. J. Neurobiol. 10: $535-550$.

Kaczmarek, L. K., K. R. Jennings, F. Strumwasser, A. Nairn, U. Walter, F. D. Wilson, and P. Greengard (1980) Microinjection of protein kinase enhances action potentials of bag cell neurons in culture. Proc. Natl. Acad. Sci. U. S. A. 77: 7487-7492.

Kupfermann, I., and E. R. Kandel (1970) Electrophysiological properties and functional interconnections of two symmetrical neurosecretory clusters (bag cells) in the abdominal ganglion of Aplysia. J. Neurophysiol. 33: 865-876.

Lemay, A., M. Deschenes, S. Lemaire, G. Poirier, L. Poulin, and F. Labrie (1974) Phosphorylation of adenohypophyseal plasma membranes and properties of associated protein $\mathrm{ki}$ nase. J. Biol. Chem. 249: 323-328.

Levitan, I. B., and S. H. Barondes (1974) Octopamine- and serotonin-stimulated phosphorylation of a specific protein in the abdominal ganglion of Aplysia californica. Proc. Natl. Acad. Sci. U. S. A. 71: 1145-1148.

Loh, P., Y. Sarne, M. P. Daniels, and H. Gainer (1977) Subcellular fractionation studies related to the processing of neurosecretory proteins in Aplysia neurons. J. Neurochem. 29: 135-139.

Mandelbaum, D. E. (1980) Studies of the role of cyclic AMP and protein phosphorylation in the mediation of food arousal in Aplysia. Doctoral thesis, Columbia University, New York.

Meech, R. W. (1972) Intracellular calcium injection causes increased potassium conductance in Aplysia nerve cells. Comp. Biochem. Physiol. (A) 42: 493-499.

Neary, J. T., T. Crow, and D. L. Alkon (1980) Biochemical correlates of a long term associative behavioral modification in Hermissenda: Changes in the levels of specific phosphoprotein bands following a conditioning procedure. Soc. Neurosci. Abstr. 6: 591.

Paris, C. G., E. R. Kandel, and J. H. Schwartz (1980) Serotonin stimulates phosphorylation of a 137,000 dalton membrane protein in the abdominal ganglion of Aplysia. Soc. Neurosci. Abstr. 6: 844 .

Ram, J. L., and Y. H. Ehrlich (1978) Cyclic GMP-stimulated phosphorylation of membrane-bound proteins from nerve roots of Aplysia californica. J. Neurochem. 30: 487-491.

Rubin, C. S., and O. M. Rosen (1975) Protein phosphorylation. Annu. Rev. Biochem. 44: 831-887.

Rudolph, S. A., and B. K. Kreuger (1979) Endogenous protein phosphorylation and dephosphorylation. Adv. Cyclic Nucleotide Res. 10: 107-133.

Schulman, H., and P. Greengard (1978a) $\mathrm{Ca}^{2+}$-dependent protein phosphorylation system in membranes from various tissues, and its activation by "calcium-dependent regulator." Proc. Natl. Acad. Sci. U. S. A. 75: 5432-5436.

Schulman, H., and P. Greengard (1978b) Stimulation of brain membrane protein phosphorylation by calcium and an endogenous heat-stable protein. Nature 271: 478-479.

Smyth, D. G., W. H. Stein, and S. Moore (1963) The sequence of amino acid residues in bovine pancreatic ribonuclease: Revisions and confirmations. J. Biol. Chem. 238: 227-234.

Strumwasser, F., L. K. Kaczmarek, K. R. Jennings, and A. Y. Chiu (1981) Studies of a model peptidergic neuronal system, the bag cells of Aplysia. In Neurosecretion: Molecules, Cells, System, K. Lederis and D. S. Farner, eds., pp. 251-270, Plenum Press, New York.

Tada, M., M. A. Kirchberger, and A. M. Katz (1975) Phosphorylation of a 22,000 dalton component of the cardiac sarcoplasmic reticulum by adenosine $3^{\prime}: 5^{\prime}$-monophosphate-dependent protein kinase. J. Biol. Chem. 250: 2610-2647.

Ward, S., D. L. Wilson, and J. J. Gilliam (1970) Methods for fractionation and scintillation counting of radioisotope-labeled polyacrylamide gels. Anal. Biochem. 38: 90-97.

Weller, M. (1979) Protein Phosphorylation, Pion Press Ltd., London. 